\title{
The effect of surgeon volume on mortality for off-pump coronary artery bypass grafting
}

\author{
Damien J. LaPar, MD, MSc, ${ }^{\mathrm{a}}$ Carlos M. Mery, MD, MPH, ${ }^{\mathrm{a}}$ Benjamin D. Kozower, MD, MPH, ${ }^{\mathrm{a}}$ \\ John A. Kern, MD, ${ }^{a}$ Irving L. Kron, MD, ${ }^{a}$ George J. Stukenborg, $\mathrm{PhD},{ }^{\mathrm{b}}$ and Gorav Ailawadi, $\mathrm{MD}^{\mathrm{a}}$
}

\begin{abstract}
Objective: Recent trials comparing on-pump (CABG) with off-pump coronary artery bypass grafting (OPCAB) have been criticized by those who believe that surgeon inexperience may explain the apparent worse outcomes for OPCAB. However, the true effect of surgeon volume on outcomes after OPCAB remains unknown. The purpose of this study was to examine the effect of surgeon volume on risk-adjusted mortality after OPCAB.
\end{abstract}

Methods: From 2003 to 2007, 709,483 patients underwent coronary artery bypass grafting operations $(\mathrm{CABG}=439,253$; OPCAB $=270,230)$ within the Nationwide Inpatient Sample database. Hierarchic generalized linear regression modeling with spline functions for annual individual operating surgeon volume was used to assess the relationship between annual surgeon volume and inpatient mortality, adjusted for comorbid disease and other potential confounders.

Results: OPCAB was performed in $38.1 \%$ of coronary artery bypass grafting operations. The average age for those undergoing OPCAB was $66.1 \pm 11.1$ years, and female patients accounted for $29.3 \%$ of operations with 1vessel $(20.4 \%)$, 2-vessel $(36.6 \%)$, 3-vessel $(20.5 \%)$, or 4 vessels or more (13.6\%). Median surgeon volume for OPCAB was 105 (56-156) operations per year. A highly significant nonlinear relationship between surgeon volume and risk-adjusted mortality was observed for OPCAB operations $(P<.01)$. Specifically, an estimated $5 \%$ decrease in the absolute probability of death occurred after OPCAB performed by the surgeons with the highest volume, which is greater than the 3\% estimated decrease for conventional CABG. Of note, the effect of surgeon volume on mortality was significantly less than other risk factors, such as the presence of heart failure, renal failure, type of bypass conduit, and gender.

Conclusions: A significant surgeon volume-outcome relationship exists for mortality after OPCAB with a threshold of more than 50 operations per year. However, the contribution of surgeon volume to the probability of death is incrementally small compared with other patient and operative characteristics. This demonstrates that outcomes after OPCAB are more dependent on patient risk factors than on surgeon volume. ( $\mathrm{J}$ Thorac Cardiovasc Surg 2012;143:854-63)

Surgeon preference to perform coronary artery bypass grafting $(\mathrm{CABG})$ with or without the use of cardiopulmonary bypass $(\mathrm{CPB})$ is motivated by many factors. Proponents of off-pump coronary artery bypass (OPCAB) frequently cite specific benefits over conventional CABG

From the Division of Thoracic and Cardiovascular Surgery, ${ }^{\mathrm{a}}$ and Department of Public Health Sciences, ${ }^{\mathrm{b}}$ University of Virginia, Charlottesville, Va.

This study was supported by Award Number 2T32HL007849-11A1 (to I.L.K.) from the National Heart, Lung, and Blood Institute and the Thoracic Surgery Foundation for Research and Education Research Grant (to G.A.). The content is solely the responsibility of the authors and does not necessarily represent the official views of the National Heart, Lung, and Blood Institute or the National Institutes of Health.

Disclosures: Authors have nothing to disclose with regard to commercial support.

Read at the 91st Annual Meeting of The American Association for Thoracic Surgery, Philadelphia, Pennsylvania, May 7-11, 2011.

Received for publication May 9, 2011; revisions received Nov 7, 2011; accepted for publication Dec 21, 2011; available ahead of print Feb 17, 2012.

Address for reprints: Gorav Ailawadi, MD, PO Box 800679, Charlottesville, VA 22908-0679 (E-mail: gorav@ virginia.edu).

$0022-5223 / \$ 36.00$

Copyright @ 2012 Published by Elsevier Inc. on behalf of The American Association for Thoracic Surgery

doi:10.1016/j.jtcvs.2011.12.048 with CPB. Certain patient populations may derive disproportionate benefits from the performance of OPCAB over conventional $\mathrm{CABG}$, including high-risk patients undergoing cardiac surgery, female patients, octogenarians, and patients with renal failure. ${ }^{1-3}$ Thus, OPCAB may become more common with an increasing number of centers performing minimally invasive and robotic $\mathrm{OPCAB}$ in the not too distant future. Although several clinical trials and institutional reports have attempted to definitively compare the safety and efficacy of both approaches, ${ }^{4-8}$ reported outcomes comparing OPCAB with CABG remain mixed. In an effort to explain the disparate differences in outcomes, some have suggested that surgeon experience plays a role and emphasized the importance of surgeon volume in establishing favorable outcomes for OPCAB. ${ }^{9-11}$

Volume-outcome relationships within surgical practice are well known. Studies investigating volume at the individual surgeon or hospital level are attractive to physicians and administrators because they allow for an intuitive measure of "expertise" and a proxy of enhanced safety and quality. 


\section{Abbreviations and Acronyms \\ $\mathrm{CABG}=$ coronary artery bypass grafting \\ $\mathrm{CPB}=$ cardiopulmonary bypass \\ ICD-9- = International Classification of \\ CM Diseases-Ninth Revision, Clinical \\ Modification \\ ITA $=$ internal thoracic artery \\ NIS = Nationwide Inpatient Sample \\ $\mathrm{OPCAB}=$ off-pump coronary artery bypass}

Relationships between surgeon volume and risk-adjusted outcomes for cardiovascular procedures have been described. In one large series, using Medicare claims data, Birkmeyer and colleagues ${ }^{12}$ demonstrated the association between annual surgeon volume and operative mortality among several different surgical populations, including those undergoing $\mathrm{CABG}$ and aortic valve replacements. Furthermore, other studies have corroborated a significant surgeon-volume relationship for on-pump CABG in the past. ${ }^{13-15}$ However, comprehensive examinations of the effect of surgeon volume on OPCAB outcomes remain underreported.

The purpose of this study was to assess the relationship between annual surgeon operative volume for the performance of OPCAB and the probability of in-hospital mortality after comprehensive adjustments for potential confounding by differences in patient- and operationrelated characteristics. Accordingly, a multi-state patient population undergoing surgical myocardial revascularization was analyzed to test whether risk-adjusted mortality after isolated bypass grafting operations is significantly associated with individual surgeon operative volume.

\section{MATERIALS AND METHODS \\ Data Source}

Patient discharge records reported for in-hospital admissions from 2003 to 2007 included in the Nationwide Inpatient Sample (NIS) databases were evaluated. The NIS represents a $20 \%$ stratified random sample of all hospital discharges in the United States, and collection, validation, and maintenance of the datasets are performed by the Agency for Healthcare Research and Quality. ${ }^{16}$ The NIS datasets represent the largest publicly available inpatient care databases within the United States. Each year the NIS captures patient discharges reported from approximately 1000 American Hospital Association hospitals. The NIS data use national hospital survey strata to weight each of the participating hospitals. Sampling strata include 5 hospital characteristics: geographic region, urban or rural location, ownership/control, teaching status, and hospital bed size. Weights are provided for each discharge record, allowing nationally representative study populations to be produced.

This study was exempt from formal review by the University of Virginia Institutional Review Board because it failed to meet the regulatory definition of human subjects research because patient identifiers were absent and the data were collected for purposes other than research.

\section{Patients}

Analysis of the effect of surgeon volume on mortality included 11 states that specifically reported unique physician identifiers for the study time period: Florida, Iowa, Kentucky, Maryland, New Hampshire, Nevada, New York, Pennsylvania, Texas, Virginia, and West Virginia. States were excluded from analysis where principle surgeons were not identified or reported surgeon identifiers may have represented surgeon groups or failed to reliably track individual surgeons throughout multiple hospitals. The study included discharge records in NIS datasets from 2003 to 2007 with selected International Classification of Diseases, 9th Revision, Clinical Modification (ICD-9-CM) procedure and diagnostic codes. Discharge records for patients with CABG procedures were identified using the following ICD-9-CM procedure codes: 30.10, 36.11, 36.12, 36.13, 36.14, 36.15, or 36.16. The concomitant use of CPB support was identified by records that also included the following ICD-9-CM procedure codes for bypass support: 39.61 or 39.66. Discharge records for patients with concomitant cardiac valve procedures (ICD-9-CM codes 35.20, 35.21, 35.22, 35.23, $35.24,35.25,35.26,35.27,35.28,35.11,35.12,35.13,35.14)$ or other cardiotomy (ICD-9-CM code 37.11) for purposes other than CPB were excluded. Patients were stratified by the use of CPB into OPCAB and CABG with CPB support cohorts for descriptive purposes. The presence of patient comorbid disease was assessed using Agency for Healthcare Research and Quality comorbid disease categories developed by Elixhauser and colleagues. $^{17}$

\section{Hospitals}

Hospital-level details were obtained through data available within the NIS database. Hospitals were defined as teaching hospitals if they were identified as having an American Medical Association-approved residency program, membership in the Council of Teaching Hospitals, or a $25 \%$ or greater ratio of full-time equivalent interns and residents to patient beds. Hospital bed size categories (small, medium, large) are defined in the NIS on the basis of the proportion of short-term, acute beds available at a given hospital. Surgeon and hospital operative volume were determined by calculating the annual total number of isolated CABG operations performed in each year of data. Hospital volume was categorized into quartiles for descriptive purposes: low ( $<25$ th percentile), medium $(26-49$ th percentile), high (50-74th percentile), and very high ( $>75$ th percentile).

\section{Outcomes Measured}

The primary outcome of interest in this study was the probability of in-hospital death. Secondary outcomes of interest included observed differences in patient comorbid disease, CABG-related details, hospital characteristics, and overall mortality rates and hospital lengths of stay for study groups. In-hospital death and hospital length of stay were identified from individual discharge records.

\section{Statistical Analysis}

Descriptive statistics. Descriptive statistics for continuous variables are reported as means \pm standard deviation or as medians (interquartile range) for skewed data. Differences in means were assessed using single factor analysis of variance or the Wilcoxon rank-sum test. Descriptive statistics for categoric variables are reported as percentages. Differences in proportions were compared using Pearson's chi-square and Fisher exact tests.

Multiple regression analysis. Hierarchic generalized multiple linear regression models were developed to assess the relationship between surgeon volume and risk-adjusted probability of in-hospital death. Separate models were developed for cohorts of patients undergoing OPCAB or CABG in each calendar year. The relationship between surgeon volume and the probability of in-hospital death was represented as a nonlinear polynomial function using restricted cubic spline transformations of the 
volume measure. A common practice in the analysis of continuous data is to distribute exposure into a series of percentile categories (eg, terciles, quartiles). Conversion of continuous data into categoric data, however, results in a loss of power to detect differences within and between categories. Spline functions use all data points to estimate the shape of an association between an exposure (surgeon volume) and an outcome (mortality). ${ }^{18}$ The use of splines provides a more robust method to determine whether nonlinearity exists between a continuous variable and a dependent outcome. ${ }^{19-21}$

For each statistical model, preoperative variables considered potential confounders for the effect of surgeon volume on mortality were selected a priori and entered as model covariates. The following covariates were included as potential confounders: number of grafts, single internal thoracic artery (ITA), double ITA, elective status, gender, and 30 categories of comorbid disease measured using the Elixhauser method. All covariates contributing cases to each estimated outcome, including nonsignificant variables, were retained in the final models. Hierarchic generalized linear regression models were used to provide appropriate adjustments for the hospital-specific variance components estimated from the weighted study population. Test statistics (F tests) obtained for each model covariate were used to determine the relative predictive strength of each covariate and to assess the statistical significance of the adjusted effect of the covariate on the risk of in-hospital death. The maximum possible change in mortality risk associated with changes in surgeon volume was measured using the full mortality risk-adjustment model. The adjusted probability of mortality was calculated for each patient using the full hierarchic generalized linear model, for each year of available data, for OPCAB and CABG cases. The minimum and maximum estimated probability of death associated with the level of surgeon volume, controlling for all other factors, were then assessed for the average patient. The absolute difference between the minimum and maximum predicted risk of death represents the maximum possible change in patient mortality risk associated with changing the level of surgeon volume from the lowest to highest level of volume for the average patient. All statistical analyses were performed using SAS version 9.2 (SAS Institute, Inc, Cary, NC).

\section{RESULTS}

\section{Patient, Hospital, and Operative Characteristics}

Descriptive statistics for all patient, hospital, and operative characteristics are detailed in Table 1 . A weighted total of 270,230 patients underwent OPCAB operations, whereas 439,253 patients underwent CABG procedures. The distribution of isolated operations by operative year were $161,505(22.8 \%)$ for $2003,144,547(20.4 \%)$ for 2004 , $126,107(17.8 \%)$ for $2005,153,987(21.7 \%)$ for 2006 , and $123,336(17.4 \%)$ for 2007 , and were consistently lower than the performance of CABG $(P<.001)$. The average patient age for both patient cohorts was 66 years. Female patients represented $29.3 \%$ of cases. The distribution of annual surgeon volume displayed a prominent rightward skew for both OPCAB and CABG. Thus, the number of surgeons performing operations at the high end of the surgeon volume distribution was comparatively small (Figure 1). Annual median surgeon volume was 105 for OPCAB and 110 for $\mathrm{CABG}$ procedures. Patients undergoing $\mathrm{CABG}$ had significantly higher odds of undergoing elective operations (odds ratio, 1.44; confidence interval, 1.42-1.50). Patients with multivessel revascularization more commonly underwent $\mathrm{CABG}$ procedures compared with OPCAB.
Few differences existed in the percentage of patients with comorbid disease in the OPCAB and CABG groups. Common major comorbid diseases included chronic pulmonary disease $(22.6 \%)$, diabetes $(28.7 \%)$, hypertension $(67.2 \%)$, and renal failure $(7.5 \%)$. The majority of procedures were performed in urban settings and at highvolume hospitals.

\section{Effect of Surgeon Volume on Risk-Adjusted Mortality}

A statistically significant relationship between surgeon volume and in-hospital mortality for OPCAB cases was observed for 3 of the 5 years $(2004,2006,2007)$. Significant relationships between surgeon volume and in-hospital mortality for CABG cases were observed for 4 of 5 years (2003, $2004,2006,2007)$. Table 2 details the results of the multiple regression models for the years 2004, 2006, and 2007 among OPCAB cases. In each model, a highly significant nonlinear relationship between surgeon volume and riskadjusted mortality was observed for OPCAB operations (2004: $P=.01,2006: P=.0004,2007: P=.005)$ after adjustment for a total of 38 different patient and operative characteristics.

Comparison of the test statistic values obtained for each covariate demonstrates that surgeon volume contributed less to the predictive performance of the model than other patient- and operation-related factors. For example, in the 2004 data, the test statistic for surgeon volume $(F=11)$ was relatively small compared with that of other highly statistically significant covariates, including renal failure $(\mathrm{F}=210, P<.0001)$, hypertension $(\mathrm{F}=180, P<.0001)$, female gender $(\mathrm{F}=102, P<.0001)$, use of single $(\mathrm{F}=156, P<.0001)$ or double $(\mathrm{F}=32, P<.0001)$ ITAs, or performance of elective operations $(\mathrm{F}=31$, $P<.0001)$. Similar results were obtained for the effect of surgeon volume on CABG operations: 2003 (F = 16, $P=.001), 2004(\mathrm{~F}=22, P=.0001), 2005(\mathrm{~F}=7$, $P=.06), 2006(\mathrm{~F}=19, P<.0001)$, and $2007(\mathrm{~F}=13$, $P=.002)$.

Figure 2 displays the spline functions for the unadjusted relationship between mortality risk and surgeon procedure volume, for the OPCAB and CABG groups, for years with statistically significant surgeon volume-outcome relationships (2004, 2006, and 2007). The functions illustrate the nonlinear shape of the relations and pattern of decreased risk of death. On the basis of these relationships, a threshold for the greatest change in unadjusted mortality risk appeared to occur after more than 50 OPCAB operations per year, and the lowest probability of death was associated with surgeon volumes of $150 \mathrm{OPCAB}$ operations or more per year. Of note, the confidence intervals dramatically widened for surgeon volumes greater than 150 to 200 operations per year, reflecting the small number surgeons with such operative volumes. For CABG operations, similar 
TABLE 1. Descriptive statistics for patients undergoing off-pump or on-pump coronary artery bypass grafting

\begin{tabular}{|c|c|c|c|}
\hline Variable & OРCAB & CABG & OR $(95 \%$ CI $)$ \\
\hline Unweighted frequency & 56,215 & 91,233 & \\
\hline Weighted frequency & 270,230 & 439,253 & \\
\hline Age $(y)^{*}$ & $66.1 \pm 11.1$ & $66.1 \pm 10.7$ & \\
\hline Female & $30.3 \%$ & $28.2 \%$ & $0.90(0.89-0.91)$ \\
\hline Elective operation & $41.7 \%$ & $50.6 \%$ & $1.44(1.42-1.50)$ \\
\hline $\begin{array}{l}\text { Surgeon operative } \\
\text { volume } \dagger\end{array}$ & $105(56-156)$ & $111(66-155)$ & \\
\hline \multicolumn{4}{|l|}{ Bypass grafts } \\
\hline 1 vessel & $19.1 \%$ & $15.6 \%$ & $0.78(0.77-0.79)$ \\
\hline 2 vessel & $34.2 \%$ & $34.6 \%$ & $1.02(1.01-1.03)$ \\
\hline 3 vessel & $27.5 \%$ & $31.5 \%$ & $1.21(1.20-1.22)$ \\
\hline$>4$ vessel & $12.7 \%$ & $15.2 \%$ & $1.23(1.21-1.25)$ \\
\hline Single ITA & $80.3 \%$ & $79.5 \%$ & $0.96(0.94-0.97)$ \\
\hline Double ITA & $3.5 \%$ & $3.0 \%$ & $0.85(0.83-0.87)$ \\
\hline Gastroepiploic & $0.1 \%$ & $<0.1 \%$ & $0.60(0.49-0.72)$ \\
\hline \multicolumn{4}{|l|}{ No. of surgeons } \\
\hline 2003 & 1937 & 2207 & \\
\hline 2004 & 1644 & 1737 & \\
\hline 2005 & 1771 & 1545 & \\
\hline 2006 & 1585 & 1496 & \\
\hline 2007 & 1516 & 1526 & \\
\hline \multicolumn{4}{|l|}{ No. of hospitals } \\
\hline 2003 & 91 & 91 & \\
\hline 2004 & 84 & 83 & \\
\hline 2005 & 72 & 72 & \\
\hline 2006 & 86 & 83 & \\
\hline 2007 & 78 & 77 & \\
\hline \multicolumn{4}{|l|}{ Operative year $\ddagger$} \\
\hline 2003 & $31.7 \%$ & $68.3 \%$ & \\
\hline 2004 & $33.0 \%$ & $67.0 \%$ & \\
\hline 2005 & $45.7 \%$ & $54.3 \%$ & \\
\hline 2006 & $41.3 \%$ & $58.7 \%$ & \\
\hline 2007 & $40.6 \%$ & $59.4 \%$ & \\
\hline \multicolumn{4}{|l|}{$\begin{array}{l}\text { Elixhauser comorbid } \\
\text { categories }\end{array}$} \\
\hline Aids & $0.1 \%$ & $0.1 \%$ & $0.65(0.45-0.78)$ \\
\hline Alcohol abuse & $2.4 \%$ & $2.0 \%$ & $0.82(0.80-0.85)$ \\
\hline Deficiency anemia & $14.8 \%$ & $12.4 \%$ & $0.82(0.81-0.83)$ \\
\hline RA and CVD & $1.3 \%$ & $1.4 \%$ & $1.10(1.05-1.14)$ \\
\hline Chronic anemia & $1.4 \%$ & $1.1 \%$ & $0.82(0.79 .0 .86)$ \\
\hline Congestive heart failure & $1.9 \%$ & $0.7 \%$ & $0.36(0.34-0.38)$ \\
\hline $\begin{array}{l}\text { Chronic pulmonary } \\
\text { disease }\end{array}$ & $24.2 \%$ & $21.7 \%$ & $0.87(0.86-0.88)$ \\
\hline Coagulopathy & $10.1 \%$ & $9.3 \%$ & $0.91(0.89-0.92)$ \\
\hline Depression & $3.8 \%$ & $3.5 \%$ & $0.93(0.90-0.95)$ \\
\hline $\begin{array}{l}\text { Diabetes } \\
\quad \text { (uncomplicated) }\end{array}$ & $27.8 \%$ & $29.3 \%$ & $1.08(1.06-1.09)$ \\
\hline Diabetes (complicated) & $5.3 \%$ & $5.2 \%$ & $0.97(0.95-0.99)$ \\
\hline Drug abuse & $0.8 \%$ & $0.6 \%$ & $0.74(0.69-0.78)$ \\
\hline Hypertension & $65.7 \%$ & $68.1 \%$ & $1.12(1.10-1.13)$ \\
\hline Hypothyroidism & $6.6 \%$ & $6.9 \%$ & $1.04(1.02-1.06)$ \\
\hline Liver disease & $0.8 \%$ & $0.6 \%$ & $0.77(0.73-0.82)$ \\
\hline Lymphoma & $0.4 \%$ & $0.3 \%$ & $0.87(0.80-0.94)$ \\
\hline
\end{tabular}

TABLE 1. Continued

\begin{tabular}{|c|c|c|c|}
\hline Variable & ОРСАВ & CABG & OR $(95 \%$ CI $)$ \\
\hline $\begin{array}{l}\text { Fluid and electrolyte } \\
\text { disorder }\end{array}$ & $19.4 \%$ & $15.5 \%$ & $0.77(0.76-0.78)$ \\
\hline Metastatic cancer & $0.2 \%$ & $0.1 \%$ & $0.73(0.64-0.82)$ \\
\hline Neurologic disorder & $2.4 \%$ & $2.1 \%$ & $0.89(0.86-0.92)$ \\
\hline Obesity & $10.6 \%$ & $10.7 \%$ & $1.00(0.99-1.02)$ \\
\hline Paralysis & $1.0 \%$ & $0.9 \%$ & $0.90(0.86-0.95)$ \\
\hline $\begin{array}{l}\text { Peripheral vascular } \\
\text { disease }\end{array}$ & $12.9 \%$ & $11.8 \%$ & $0.90(0.89-0.92)$ \\
\hline Psychoses & $1.0 \%$ & $1.0 \%$ & $0.96(0.92-1.01)$ \\
\hline $\begin{array}{l}\text { Pulmonary circulatory } \\
\text { disease }\end{array}$ & $0.1 \%$ & $<0.1 \%$ & $0.31(0.26-0.37)$ \\
\hline Renal failure & $8.7 \%$ & $6.7 \%$ & $0.75(0.74-0.77)$ \\
\hline Tumor (no metastases) & $1.0 \%$ & $1.0 \%$ & $0.98(0.93-1.03)$ \\
\hline Peptic ulcer disease & $0.1 \%$ & $<0.1 \%$ & $0.77(0.62-0.95)$ \\
\hline Valve disease & $1.0 \%$ & $0.4 \%$ & $0.34(0.32-0.37)$ \\
\hline Weight loss & $1.7 \%$ & $1.0 \%$ & $0.58(0.56-0.61)$ \\
\hline Hospital location (urban) & $96.2 \%$ & $96.4 \%$ & $1.06(1.03-1.08)$ \\
\hline $\begin{array}{l}\text { Thoracic surgery teaching } \\
\text { hospital }\end{array}$ & $8.3 \%$ & $7.8 \%$ & $0.94(0.92-0.96)$ \\
\hline \multicolumn{4}{|l|}{ Hospital region } \\
\hline Northeast & $26.0 \%$ & $26.9 \%$ & \\
\hline Midwest & $11.1 \%$ & $14.3 \%$ & \\
\hline South & $51.3 \%$ & $51.8 \%$ & \\
\hline West & $11.6 \%$ & $7.0 \%$ & \\
\hline \multicolumn{4}{|l|}{ Hospital operative volume } \\
\hline Low $(<25$ th percentile $)$ & $3.8 \%$ & $2.9 \%$ & \\
\hline $\begin{array}{l}\text { Medium (26th-50th } \\
\text { percentile) }\end{array}$ & $11.0 \%$ & $10.0 \%$ & \\
\hline $\begin{array}{l}\text { High }(51 \text { st-75th } \\
\text { percentile) }\end{array}$ & $21.5 \%$ & $20.2 \%$ & \\
\hline $\begin{array}{l}\text { Very high }(>75 \text { th } \\
\text { percentile) }\end{array}$ & $63.7 \%$ & $66.8 \%$ & \\
\hline
\end{tabular}

volume-outcome relationships were revealed and appeared more dramatic for low to medium surgeon volumes.

The magnitude of the change in risk-adjusted mortality associated with surgeon volume, adjusted for the effects of age, comorbid disease, and other confounders, was calculated using the full model equations for patients in the OPCAB and CABG study populations (Table 3). The largest possible change in the probability of death associated with a change in surgeon volume ranged between $1.3 \%$ and $5.4 \%$ for patients in the OPCAB study population and between $1.6 \%$ and $3.4 \%$ for patients in the CABG study population, depending on year. For example, the minimum estimated probability of death associated with the level of surgeon volume was $1.1 \%$ and the highest was $6.5 \%$ among average patients in the OPCAB study population for the 2003 calendar year, adjusted for all other patient characteristics. Thus, moving an average patient from the lowest to the highest (or from highest to 


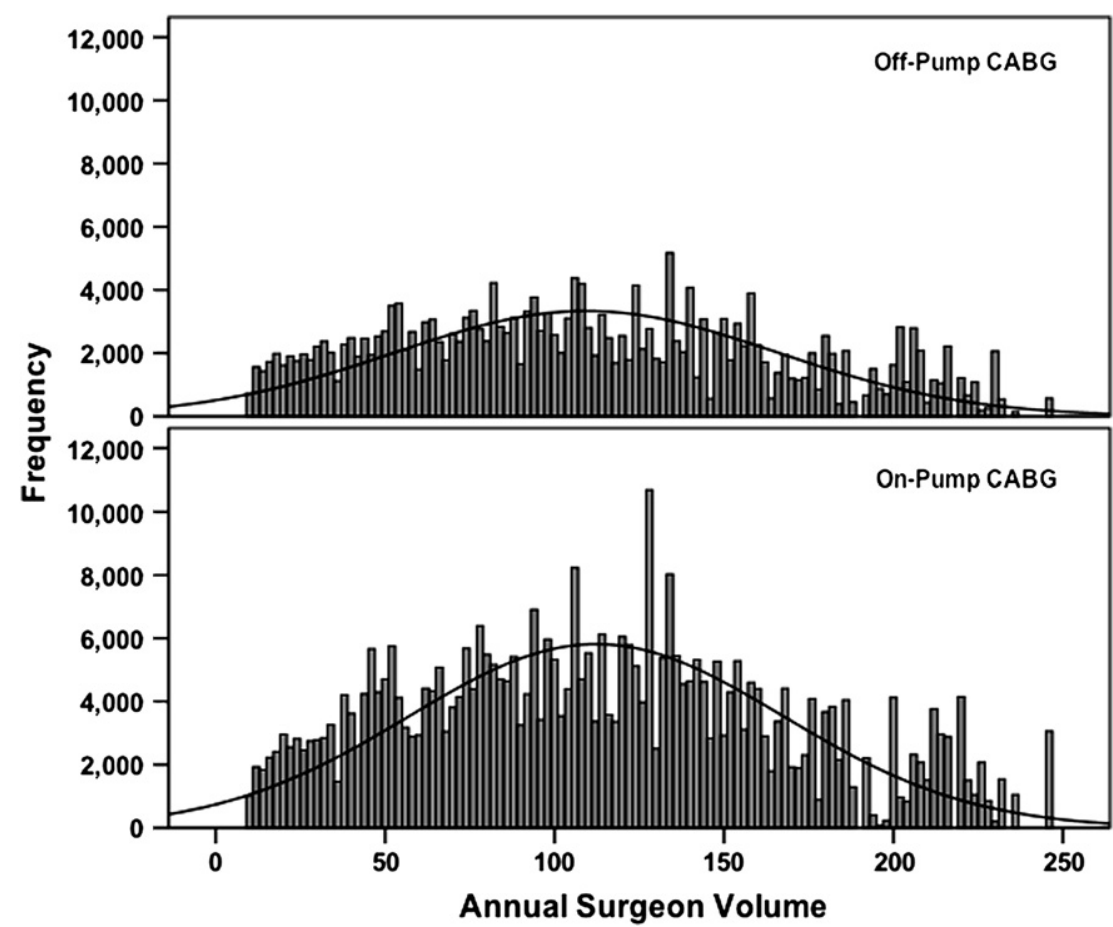

FIGURE 1. Histograms representing the distribution of annual surgeon volume for the performance of both OPCAB and conventional CABG. $C A B G$, Coronary artery bypass grafting.

lowest) possible level of surgery volume would yield a $5.4 \%$ absolute difference in the probability of death among average patients in the OPCAB study population for the 2003 calendar year.

\section{DISCUSSION}

This study provides a population-based perspective on the effect of surgeon volume on risk-adjusted mortality after OPCAB operations compared with conventional on-pump CABG. Examination of outcomes in a broadly generalizable, multi-state patient population demonstrates that individual surgeon volume has a statistically significant nonlinear relationship with risk-adjusted mortality after accounting for the potential confounding effects of 38 different patient- and operation-related factors. The largest possible change in the adjusted probability of death associated with a change in surgeon volume for OPCAB procedures appears to range from $1 \%$ to $5 \%$. Of note, however, the relative strength of this association is small compared with the effects estimated for many other wellestablished cardiac surgical risk factors. Thus, in light of continued debate regarding factors influencing outcomes for $\mathrm{CABG}$ with and without the use of $\mathrm{CPB}$, these data provide important insight into the relative impact of surgeon volume compared with other patient factors on OPCAB morality.

Accumulated data have reported varying results in comparisons of OPCAB with on-pump CABG, which has resulted in an ensuing debate regarding the comparative effectiveness of one technique over the other. Proponents of $\mathrm{OPCAB}$ cite the reduction in morbidity that may be related to the avoidance of aortic cannulation or the effects of $\mathrm{CPB}$, whereas those who prefer CABG with $\mathrm{CPB}$ often submit the reduced completeness of revascularization and graft patency with $\mathrm{OPCAB}$, as well as equivalent short- and longterm morbidity and mortality between the 2 techniques. A number of previous prospective randomized clinical trials have provided significant data to support both sides of the debate. In the Octopus trial, OPCAB was associated with shorter hospital lengths of stay and reduced mechanical ventilator requirements among a cohort of 281 patients, whereas perioperative mortality rates were similar. $^{8}$ These results were further corroborated by Puskas and colleagues $^{5,6}$ in 2 separate trials demonstrating equivalent operative and 1-year outcomes, reduced resource use, lower costs, and similar completeness of revascularization and graft patency with OPCAB. In 2 additional trials, Angelini and colleagues ${ }^{4}$ reported similar long-term outcomes despite the use of CPB among experienced surgeons. Alternatively, the recently published ROOBY trial demonstrated worse 1-year composite outcomes, completeness of revascularization, and graft patency for OPCAB, despite similar 30-day outcomes. ${ }^{7}$ Competing results between the 2 techniques also exists within several large observational studies and meta-analyses ${ }^{22,23}$; however, these series are subject to inherent surgeon and institutional biases. Thus, these results 
TABLE 2. Hierarchic logistic regression model results for off-pump coronary artery bypass in-hospital mortality

\begin{tabular}{|c|c|c|c|c|c|c|c|c|c|c|c|c|c|c|c|}
\hline \multirow[b]{3}{*}{ Covariate } & \multicolumn{5}{|c|}{2004} & \multicolumn{5}{|c|}{2006} & \multicolumn{5}{|c|}{2007} \\
\hline & \multirow[b]{2}{*}{$\mathbf{F}$} & \multirow[b]{2}{*}{$\boldsymbol{P}$} & \multirow[b]{2}{*}{ OR } & \multicolumn{2}{|c|}{$95 \% \mathrm{CI}$} & \multirow[b]{2}{*}{$\mathbf{F}$} & \multirow[b]{2}{*}{$\boldsymbol{P}$} & \multirow[b]{2}{*}{ OR } & \multicolumn{2}{|c|}{$\mathbf{9 5} \% \mathrm{CI}$} & \multirow[b]{2}{*}{$\mathbf{F}$} & \multirow[b]{2}{*}{$\boldsymbol{P}$} & \multirow[b]{2}{*}{ OR } & \multicolumn{2}{|c|}{$\mathbf{9 5} \% \mathrm{CI}$} \\
\hline & & & & Lower & Upper & & & & Lower & Upper & & & & Lower & Upper \\
\hline Surgeon volume (spline)* & 11 & .01 & NA & & & 19 & .0004 & NA & & & 13 & .0046 & NA & & \\
\hline Gender (female) & 102 & $<.0001$ & 1.94 & 1.71 & 2.20 & 22 & $<.0001$ & 1.30 & 1.16 & 1.45 & 52 & $<.0001$ & 1.52 & 1.36 & 1.71 \\
\hline \multicolumn{16}{|l|}{ Bypass grafts } \\
\hline 1 vessel & 6 & .01 & 0.68 & 0.51 & 0.92 & 1 & .2999 & 0.88 & 0.68 & 1.13 & 3 & .0843 & 0.81 & 0.64 & 1.03 \\
\hline 2 vessel & 1 & .24 & 0.85 & 0.64 & 1.12 & 01 & .4793 & 0.92 & 0.72 & 1.17 & 5 & .0215 & 0.76 & 0.61 & 0.96 \\
\hline 3 vessel & 1 & .32 & 0.87 & 0.66 & 1.15 & 7 & .0088 & 0.72 & 0.56 & 0.92 & 10 & .0014 & 0.67 & 0.53 & 0.86 \\
\hline$>4$ vessel & 1 & .30 & 0.84 & 0.62 & 1.16 & 1 & .3486 & 0.88 & 0.67 & 1.15 & 20 & $<.0001$ & 0.53 & 0.40 & 0.70 \\
\hline Single ITA & 156 & $<.0001$ & 0.42 & 0.36 & 0.48 & 317 & $<.0001$ & 0.34 & 0.31 & 0.39 & 387 & $<.0001$ & 0.29 & 0.25 & 0.33 \\
\hline Double ITA & 32 & $<.0001$ & 0.22 & 0.13 & 0.37 & 46 & $<.0001$ & 0.19 & 0.12 & 0.31 & 96 & $<.0001$ & 0.14 & 0.09 & 0.20 \\
\hline \multicolumn{16}{|l|}{ Comorbid disease } \\
\hline Elective operation & 31 & $<.0001$ & 0.66 & 0.57 & 0.76 & 29 & $<.0001$ & 0.72 & 0.64 & 0.82 & 28 & $<.0001$ & 0.72 & 0.63 & 0.81 \\
\hline AIDS & 0.3 & .6169 & 0.06 & $<0.001$ & $>999.999$ & 1 & .2835 & 0.04 & $<0.001$ & 15.71 & 1 & .3966 & 0.02 & $<0.001$ & 255.45 \\
\hline Alcohol abuse & 0.1 & .7466 & 0.94 & 0.62 & 1.41 & 3 & .0651 & 0.71 & 0.50 & 1.02 & 3 & .0847 & 0.70 & 0.46 & 1.05 \\
\hline Deficiency anemia & 25 & $<.0001$ & 0.52 & 0.40 & 0.67 & 75 & $<.0001$ & 0.44 & 0.37 & 0.53 & 39 & $<.0001$ & 0.60 & 0.51 & 0.70 \\
\hline RA and CVD & 1 & .3666 & 1.27 & 0.76 & 2.13 & 0.4 & .5525 & 1.13 & 0.75 & 1.72 & 0.1 & .7986 & 1.06 & 0.68 & 1.64 \\
\hline Chronic anemia & 2 & .1865 & 0.67 & 0.37 & 1.21 & 7 & .0094 & 0.60 & 0.41 & 0.88 & 7 & .0077 & 0.56 & 0.37 & 0.86 \\
\hline Congestive heart failure & 15 & $<.0001$ & 2.02 & 1.42 & 2.87 & 199 & $<.0001$ & 4.32 & 3.52 & 5.29 & 88 & $<.0001$ & 3.17 & 2.49 & 4.04 \\
\hline $\begin{array}{l}\text { Chronic pulmonary } \\
\text { disease }\end{array}$ & 9 & .0034 & 0.80 & 0.69 & 0.93 & 1 & .3875 & 1.05 & 0.94 & 1.18 & 1 & .2675 & 1.07 & 0.95 & 1.21 \\
\hline Coagulopathy & 47 & $<.0001$ & 1.84 & 1.55 & 2.19 & 181 & $<.0001$ & 2.30 & 2.04 & 2.60 & 137 & $<.0001$ & 2.17 & 1.91 & 2.47 \\
\hline Depression & 11 & .0008 & 0.39 & 0.22 & 0.67 & 20 & $<.0001$ & 0.40 & 0.27 & 0.59 & 34 & $<.0001$ & 0.27 & 0.17 & 0.42 \\
\hline $\begin{array}{l}\text { Diabetes } \\
\quad \text { (uncomplicated) }\end{array}$ & 40. & $<.0001$ & 0.57 & 0.47 & 0.67 & 17 & $<.0001$ & 0.76 & 0.67 & 0.87 & 60 & $<.0001$ & 0.57 & 0.49 & 0.65 \\
\hline Diabetes (complicated) & 26 & $<.0001$ & 0.44 & 0.32 & 0.60 & 15 & .0001 & 0.61 & 0.48 & 0.79 & 6 & .0135 & 0.75 & 0.60 & 0.94 \\
\hline Drug abuse & 34 & .0613 & 0.05 & 0.00 & 1.15 & 8 & .0041 & 0.26 & 0.11 & 0.65 & 7 & .0092 & 0.04 & 0.00 & 0.45 \\
\hline Hypertension & 180 & $<.0001$ & 0.40 & 0.34 & 0.45 & 150 & $<.0001$ & 0.51 & 0.45 & 0.56 & 166 & $<.0001$ & 0.47 & 0.42 & 0.53 \\
\hline Hypothyroidism & 32 & $<.0001$ & 0.23 & 0.14 & 0.38 & 0.4 & .5139 & 1.07 & 0.87 & 1.32 & 0.3 & .5698 & 0.94 & 0.76 & 1.16 \\
\hline Liver disease & 9 & .0032 & 2.06 & 1.27 & 3.33 & 44 & $<.0001$ & 3.32 & 2.33 & 4.74 & 4 & .0517 & 0.52 & 0.27 & 1.01 \\
\hline Lymphoma & 1 & .264 & 1.59 & 0.71 & 3.57 & 10 & .0015 & 2.30 & 1.38 & 3.84 & 1 & .4322 & 0.79 & 0.43 & 1.44 \\
\hline $\begin{array}{l}\text { Fluid and electrolyte } \\
\text { disorder }\end{array}$ & 124 & $<.0001$ & 2.20 & 1.91 & 2.53 & 84 & $<.0001$ & 1.71 & 1.53 & 1.92 & 171 & $<.0001$ & 2.16 & 1.92 & 2.42 \\
\hline Metastatic cancer & 2 & .1707 & 0.03 & $<0.001$ & 4.28 & 41 & $<.0001$ & 6.24 & 3.58 & 10.89 & 51 & $<.0001$ & 7.77 & 4.42 & 13.65 \\
\hline Neurologic Disorder & 33 & $<.0001$ & 2.41 & 1.78 & 3.26 & 0.02 & .8888 & 1.02 & 0.76 & 1.37 & 01 & .7796 & 1.04 & 0.78 & 1.39 \\
\hline Obesity & 23 & $<.0001$ & 0.38 & 0.26 & 0.57 & 2 & .1212 & 0.86 & 0.71 & 1.04 & 26 & $<.0001$ & 0.54 & 0.43 & 0.69 \\
\hline Paralysis & 25 & $<.0001$ & 3.17 & 2.02 & 4.99 & 25 & $<.0001$ & 2.72 & 1.83 & 4.04 & 56 & $<.0001$ & 3.50 & 2.52 & 4.85 \\
\hline $\begin{array}{l}\text { Peripheral vascular } \\
\text { disease }\end{array}$ & 17 & $<.0001$ & 1.46 & 1.22 & 1.76 & 0.3 & .5893 & 1.04 & 0.90 & 1.21 & 8 & .0053 & 1.22 & 1.06 & 1.41 \\
\hline Psychoses & 1 & .2316 & 0.59 & 0.24 & 1.41 & 10 & .0018 & 0.21 & 0.08 & 0.57 & 2 & .1352 & 0.64 & 0.35 & 1.15 \\
\hline $\begin{array}{l}\text { Pulmonary circulatory } \\
\text { disease }\end{array}$ & 0.2 & .6807 & 0.02 & $<0.001$ & $>999.999$ & 8 & .0064 & 0.36 & 0.17 & 0.75 & 1 & .4221 & 1.30 & 0.68 & 2.49 \\
\hline Renal failure & 210 & $<.0001$ & 4.19 & 3.45 & 5.08 & 143 & $<.0001$ & 2.23 & 1.96 & 2.55 & 116 & $<.0001$ & 2.09 & 1.83 & 2.39 \\
\hline Tumor (no metastases) & 34 & .0479 & 0.05 & 0.00 & 0.97 & 1 & .3857 & 1.23 & 0.77 & 1.98 & 4 & .051 & 0.57 & 0.32 & 1.00 \\
\hline Peptic ulcer disease & 0.4 & .522 & 0.09 & $<0.001$ & 132.54 & 0.1 & .7253 & 0.07 & $<0.001$ & $>999.999$ & & & & & \\
\hline Valve disease & 3 & .0736 & 1.52 & 0.96 & 2.40 & 0.8 & .3793 & 1.14 & 0.85 & 1.54 & 5 & .0222 & 0.65 & 0.45 & 0.94 \\
\hline Weight loss & 4 & .1098 & 1.38 & 0.93 & 2.04 & 15 & .0001 & 1.64 & 1.27 & 2.11 & 48 & $<.0001$ & 2.16 & 1.74 & 2.68 \\
\hline
\end{tabular}

$O R$, Odds ratio; $C I$, confidence interval; $A I D S$, acquired immune deficiency syndrome; $C V D$, collagen vascular disease; $R A$, rheumatoid arthritis; $N A$, not available. $*$ OR not interpretable for spline analysis.

have set the stage for a significant debate that has often focused on the role of surgeon experience, or inexperience, with the performance of OPCAB and the effect of surgeon volume on outcomes. Little has been published regarding this issue.
The most significant results of the present study are the repeated demonstration of a significant surgeon volumeoutcome relationship that exists for the performance of OPCAB in the modern surgical era and the magnitude of this effect relative to other determinants of patient mortality. 
OPCAB
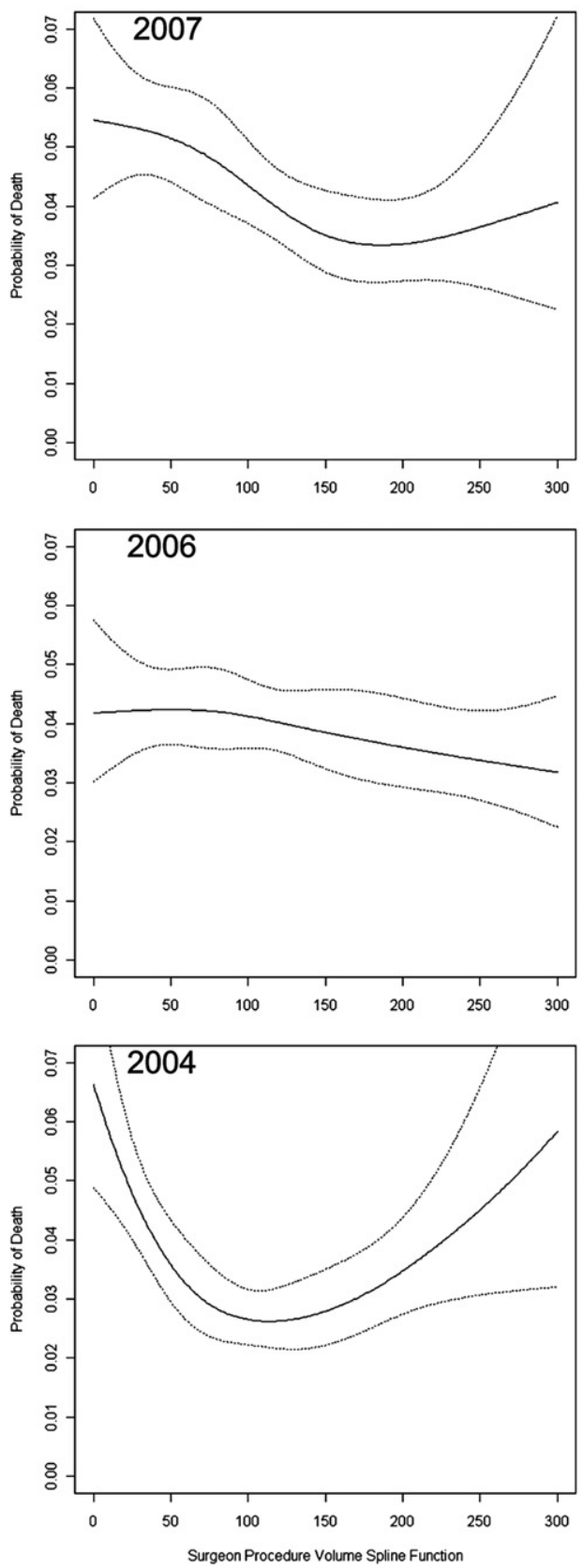

CABG
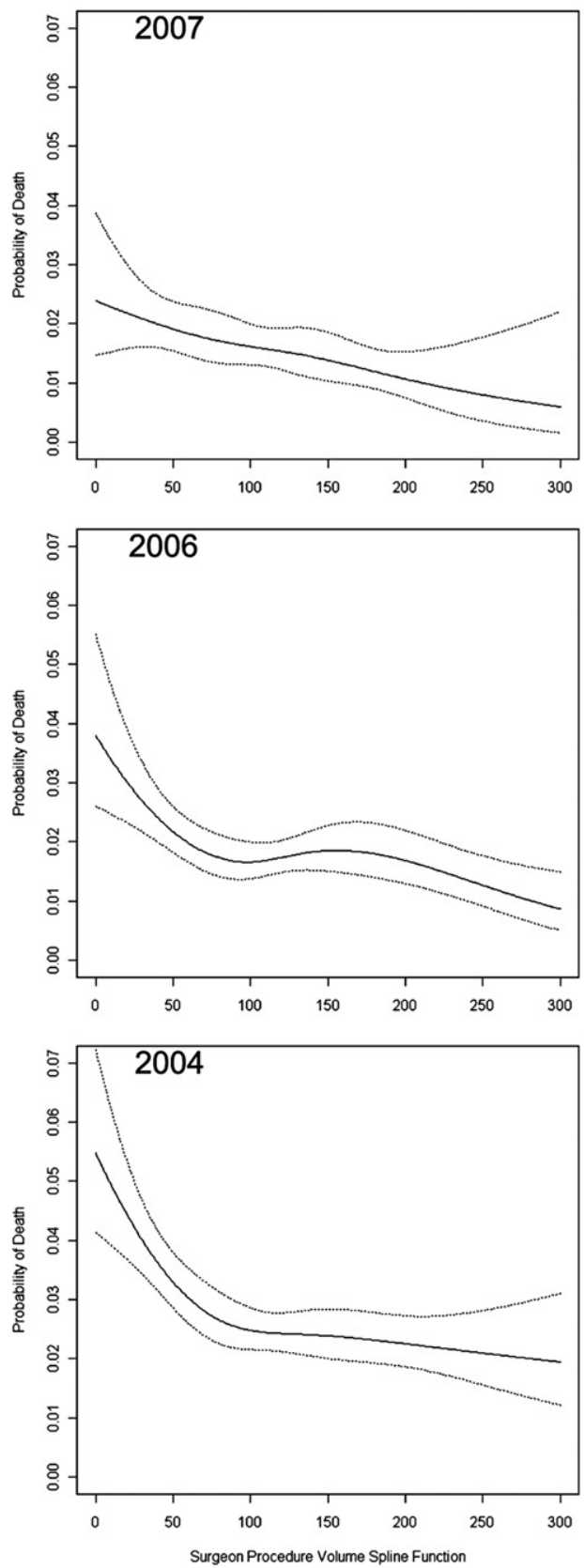

FIGURE 2. Each plot presents restricted cubic spline functions for the unadjusted relationship between surgeon volume and probability of in-hospital death. Separate plots are presented for patients undergoing OPCAB and conventional CABG in the United States for the years 2004, 2006 , and 2007. The estimated function is presented by the solid line, with dashed lines depicting the $95 \%$ confidence intervals of the functions. OPCAB, Off-pump coronary artery bypass; $C A B G$, coronary artery bypass grafting.

These results are in disagreement with a prior report from a New York State registry that failed to demonstrate a significant relationship between surgeon experience and mortality risk. ${ }^{13}$ In the present study, the effect of surgeon volume was rigorously assessed using advanced statistical modeling within a large, representative, multi-state patient population. A similar cohort of patients undergoing
CABG with $\mathrm{CPB}$ was also analyzed to validate the estimated effects for OPCAB because prior surgeon volumeoutcome relationships have been well established for conventional on-pump CABG. As a result, similar relationships were observed among both OPCAB and CABG cohorts with respect to the annual number of operations performed and the adjusted probability of in-hospital death. 
TABLE 3. Change in probability of death associated with a change in surgeon volume adjusted for all patient characteristics after performance of off-pump and on-pump coronary artery bypass grafting

\begin{tabular}{cccc}
\hline Year & $\begin{array}{c}\text { Largest possible } \\
\text { change in } \\
\text { mortality risk }\end{array}$ & $\begin{array}{c}\text { Minimum } \\
\text { probability } \\
\text { of death }\end{array}$ & $\begin{array}{c}\text { Maximum } \\
\text { probability } \\
\text { of death }\end{array}$ \\
\hline OPCAB & & & \\
2003 & $5.4 \%$ & $1.1 \%$ & $6.5 \%$ \\
2004 & $3.9 \%$ & $2.4 \%$ & $6.3 \%$ \\
2005 & $2.0 \%$ & $3.7 \%$ & $5.7 \%$ \\
2006 & $1.3 \%$ & $2.9 \%$ & $4.2 \%$ \\
2007 & $2.0 \%$ & $3.3 \%$ & $5.3 \%$ \\
CABG & & & \\
2003 & $3.3 \%$ & $1.9 \%$ & $5.2 \%$ \\
2004 & $3.4 \%$ & $1.7 \%$ & $5.1 \%$ \\
2005 & $1.8 \%$ & $0.8 \%$ & $2.6 \%$ \\
2006 & $3.1 \%$ & $0.4 \%$ & $3.5 \%$ \\
2007 & $1.6 \%$ & $0.6 \%$ & $2.2 \%$ \\
\hline$O P C A B$, Off-pump coronary artery bypass; $C A B G$, coronary artery bypass grafting.
\end{tabular}

Furthermore, to provide a true clinical estimate of the effect of surgeon volume on risk-adjusted mortality, the maximum possible effect that surgeon volume could have on mortality risk for the average patient was calculated. On the basis of these estimates, if an "average" patient undergoing $\mathrm{OPCAB}$ by a surgeon with the lowest possible volume were instead operated on by a surgeon with the highest possible volume, the absolute reduction in the probability of death could be as high as $5 \%$. In this scenario, the probability of death would be reduced from $6 \%$ to $1 \%$. A similar, yet less dramatic reduction in risk-adjusted probability of death $(3 \%)$ was estimated for those undergoing CABG operations by high- and low-volume surgeons.

Despite these significant relationships, the relative strength of association between surgeon volume and the probability of death was comparatively small relative to other patient- and operation-related risk factors. On examination of other risk factors (Table 2), the relative contribution of each covariate to the performance of a statistical model, and thus the relative strength of association between each covariate and the dependent outcome of interest (probability of death), should be noted by the calculated test statistic for each covariate. For the performance of OPCAB, the relative strength of surgeon volume ranked in the lower 50th percentile of analyzed risk factors. In fact, other wellestablished risk factors for cardiac surgical outcomes had higher relative strength within the models, including preoperative renal failure, hypertension, metabolic disturbance, congestive heart failure, female gender, diabetes, and the performance of bypass with single or double ITA. The test statistics for some of these factors were surprisingly high (ie, hypertension), which may reflect real differences, differences in hospital reporting of certain conditions associated with patients at higher risk of death, or other spurious associations. Overall, however, the results indicate that although surgeon volume may be a significant risk factor for in-hospital mortality after the performance of OPCAB, other potentially modifiable patient and operative risk factors should be more strongly considered during individual patient risk stratification and preoperative decisions regarding the performance of $\mathrm{CABG}$ with or without $\mathrm{CPB}$.

Important to consider in the interpretation of these results is the statistical methodology used to derive the reported estimated effects. Because of the complex sampling nature of the NIS datasets, hierarchic multiple regression methods were used to account for clustering of data at the surgeon and hospital levels. Unlike the methodology used in prior reports of the effect of surgeon volume on OPCAB outcomes,${ }^{13}$ the use of restricted cubic spline functions within the models of the present study allowed for the adequate assessment of surgeon volume as a continuous variable within the model. Cubic spline functions are often used to assess the shape and strength of relationships that exist between continuous predictor variables and dependent outcomes of interest. ${ }^{18,24}$ These functions allow for the representation of nonlinear relationships between continuous variables and outcomes to provide for a robust final multiple regression model. As a result, in the present study, a significant nonlinear relationship was demonstrated between individual surgeon volume and probability of death; however, no significant linear relationships were revealed. The fact that surgeon volume was not significant for OPCAB or CABG when analyzed as a linear function underscores the importance of using such nonlinear transformations of continuous data to better characterize the nature of subtle volume-outcome relationships and to provide more precise estimates of effects. More important, the representation of surgeon volume as a continuous variable within these models avoided the inherent problems of categorizing such data for subsequent analysis. An allto-common practice in medical and surgical literature, categorization of continuous data is often arbitrary and ineffective in adequately defining statistical relationships. ${ }^{19,25}$ With respect to an issue such as surgeon- or hospitalrelated volume-outcome relationships, such practice may lead to inappropriate conclusions that may have significant implications on clinical practice, surgical referral patterns, and hospital quality assessment.

\section{Study Limitations}

This study has select limitations and considerations that deserve further discussion. The influence of selection bias in any large, observational analysis cannot be dismissed. Furthermore, the inherent selection bias represented at the surgeon level for the performance of OPCAB versus CABG must be considered in any such comparative analysis. Further, the potential for unrecognized miscoding of diagnostic and procedure codes must be recognized in any 
secondary analysis of administrative data. Despite the number of factors that seem to have a significant negative impact on mortality, the performance of elective operations and the use of ITA grafts would be associated with improved odds of mortality. In addition, the use of a large administrative database to scrutinize curious or surprising results, such as the apparently low ITA use in this study or conversion rates from OPCAB to CABG, is limited, as well as the ability to risk-adjust for certain cardiac surgical risk factors, including preoperative ejection fraction, New York Heart Association functional class, cannulation and clamping strategies, CPB time, bypass graft harvesting technique, and the influence of medications known to affect cardiac surgical outcomes. Surgeon volume for OPCAB was not statistically significant for each year analyzed, which further suggests that the statistically significant relationship between annual surgeon volume and probability of death after $\mathrm{OPCAB}$ is incrementally small compared with other well-established risk factors that were associated with mortality for all operative years. Further, because of the nature of the NIS database and the fact that unique surgeon identifiers could only be reliably tracked within a given year, it was necessary to analyze the effect of surgeon volume within each operative year separately as opposed to pooling data from all operative years. Likewise, both OPCAB and CABG cohorts were analyzed separately. Finally, the relatively high percentage of OPCAB operations represented in this dataset should be considered. This likely reflects the exclusion of many states because of imprecise individual surgeon volume reporting. Nevertheless, in the assessment of surgeon volume and its effect on risk-adjusted mortality, the use of NIS provides great strength in its ability to capture a large, broadly generalizable patient population and surgeons with a great range of experience. As a result, these analyses provide important insight into an unanswered question regarding the influence of annual surgeon volume on reported outcomes for the performance of $\mathrm{OPCAB}$ and $\mathrm{CABG}$ procedures.

\section{CONCLUSIONS}

The present results demonstrate that a significant surgeon volume-outcome relationship exists for mortality after surgical myocardial revascularization, particularly for $\mathrm{OPCAB}$, with an apparent threshold of more than 50 operations per year. Performance of OPCAB by the highest volume surgeons may result in an absolute reduction in the probability of death of approximately $1 \%$ to $5 \%$, which is greater than that estimated for the performance of conventional on-pump CABG. Despite these estimates, the contribution of surgeon volume to the probability of death is incrementally small compared with other patient and operative characteristics. Thus, outcomes after OPCAB seem to reflect the greater influence of risk factors other than surgeon volume.

\section{References}

1. LaPar DJ, Bhamidipati CM, Reece TB, Cleveland JC, Kron IL, Ailawadi G. Is off-pump coronary artery bypass grafting superior to conventional bypass in octogenarians? J Thorac Cardiovasc Surg. 2011;141:81-90.

2. Puskas JD, Kilgo PD, Kutner M, Pusca SV, Lattouf O, Guyton RA. Off-pump techniques disproportionately benefit women and narrow the gender disparity in outcomes after coronary artery bypass surgery. Circulation. 2007;116(11 Suppl):I192-9.

3. Puskas JD, Thourani VH, Kilgo P, Cooper W, Vassiliades T, Vega JD, et al. Offpump coronary artery bypass disproportionately benefits high-risk patients. Ann Thorac Surg. 2009;88:1142-7.

4. Angelini GD, Culliford L, Smith DK, Hamilton MC, Murphy GJ, Ascione R, et al. Effects of on- and off-pump coronary artery surgery on graft patency, survival, and health-related quality of life: long-term follow-up of 2 randomized controlled trials. J Thorac Cardiovasc Surg. 2009;137:295-303.

5. Puskas JD, Williams WH, Duke PG, Staples JR, Glas KE, Marshall JJ, et al. Offpump coronary artery bypass grafting provides complete revascularization with reduced myocardial injury, transfusion requirements, and length of stay: a prospective randomized comparison of two hundred unselected patients undergoing off-pump versus conventional coronary artery bypass grafting. J Thorac Cardiovasc Surg. 2003;125:797-808

6. Puskas JD, Williams WH, Mahoney EM, Huber PR, Block PC, Duke PG, et al. Off-pump vs conventional coronary artery bypass grafting: early and 1-year graft patency, cost, and quality-of-life outcomes: a randomized trial. JAMA. 2004;291: 1841-9.

7. Shroyer AL, Grover FL, Hattler B, Collins JF, McDonald GO, Kozora E, et al. On-pump versus off-pump coronary-artery bypass surgery. $N$ Engl J Med. 2009;361:1827-37.

8. van Dijk D, Nierich AP, Jansen EW, Nathoe HM, Suyker WJ, Diephuis JC, et al. Early outcome after off-pump versus on-pump coronary bypass surgery: results from a randomized study. Circulation. 2001;104:1761-6.

9. Puskas JD, Mack MJ, Smith CR. On-pump versus off-pump CABG. $N$ Engl J Med. 2010;362:851. author reply 53-4.

10. Taggart DP. On-pump versus off-pump CABG. N Engl J Med. 2010;362:852. author reply 53-4.

11. Kieser TM. On-pump versus off-pump CABG. N Engl J Med. 2010;362:852. author reply 53-4.

12. Birkmeyer JD, Stukel TA, Siewers AE, Goodney PP, Wennberg DE, Lucas FL. Surgeon volume and operative mortality in the United States. $N$ Engl J Med. 2003;349:2117-27.

13. Glance LG, Dick AW, Osler TM, Mukamel DB. The relation between surgeon volume and outcome following off-pump vs on-pump coronary artery bypass graft surgery. Chest. 2005;128:829-37.

14. Hannan EL, Wu C, Ryan TJ, Bennett E, Culliford AT, Gold JP, et al. Do hospitals and surgeons with higher coronary artery bypass graft surgery volumes still have lower risk-adjusted mortality rates? Circulation. 2003;108:795-801.

15. Hockenberry JM, Lien HM, Chou SY. Surgeon and hospital volume as quality indicators for CABG in Taiwan: examining hazard to mortality and accounting for unobserved heterogeneity. Health Serv Res. 2010;45(5 Pt 1): 1168-87.

16. Whalen D, Houchens R, Elixhauser A. 2004 HCUP Nationwide Inpatient Sample (NIS) Comparison Report HCP Methods Series Report \#2007-03. Available at: http://www.hcup-us.ahrq.gov/reports/methods.jsp. Accessed April 27, 2011.

17. Elixhauser A, Steiner C, Harris DR, Coffey RM. Comorbidity measures for use with administrative data. Med Care. 1998;36:8-27.

18. Greenland S. Dose-response and trend analysis in epidemiology: alternatives to categorical analysis. Epidemiology. 1995;6:356-65.

19. Filardo G, Hamilton C, Hamman B, Ng HK, Grayburn P. Categorizing BMI may lead to biased results in studies investigating in-hospital mortality after isolated CABG. J Clin Epidemiol. 2007;60:1132-9.

20. Kozower B, Stukenborg GJ. The relationship between hospital lung cancer resection volume and patient mortality risk. Ann Surg. 2011;254:1032-7.

21. Stukenborg GJ, Wagner DP, Harrell FE. Temporal order and non-linearity in the relationship between lung cancer resection volume and in-hospital mortality. Health Serv Outcomes Res Methodol. 2004;5:59-73.

22. Puskas JD, Kilgo PD, Lattouf OM, Thourani VH, Cooper WA, Vassiliades TA, et al. Off-pump coronary bypass provides reduced mortality and morbidity and equivalent 10-year survival. Ann Thorac Surg. 2008;86:1139-46.

23. Reston JT, Tregear SJ, Turkelson CM. Meta-analysis of short-term and mid-term outcomes following off-pump coronary artery bypass grafting. Ann Thorac Surg. 2003;76:1510-5. 
24. Lee DS, Austin PC, Rouleau JL, Liu PP, Naimark D, Tu JV. Predicting mortality among patients hospitalized for heart failure: derivation and validation of a clinical model. JAMA. 2003;290:2581-7.

25. O'Brien SM. Cutpoint selection for categorizing a continuous predictor. Biometrics. 2004;60:504-9.

\section{Discussion}

Dr R. Morton Bolman (Boston, Mass). This is a nice study examining the effect of surgeon volume on outcomes after both onpump CABG and OPCAB. Your findings that the median volumes were 105 cases per surgeon were interesting and represented that this was a relatively unusual population in that regard. There was an incidence of $38 \%$ of OPCAB in this population, which is approximately twice the percentage across the Society of Thoracic Surgeons' database in the United States. In that light, do you think this is representative of what is going on across the United States in terms of your outcome?

Dr LaPar (Charlottesville, Va). Those are important observations in our data. I would absolutely echo the fact that the higher percentage or high proportion of OPCAB cases represented in this analysis is higher than in other reported series. It may not necessarily be representative of what is occurring nationwide. As I mentioned, we did have to exclude some states that didn't report, and that may have skewed the data in some respect. However, skewing that data may have helped us to detect subtle relationships and to quantify the surgeon-outcome relationship, because it allowed us to analyze a higher percentage of OPCAB cases.

Dr Bolman. As you mentioned, you found that patients undergoing operations between the surgeons with the highest and lowest volume off-pump experience might have as much as a $5 \%$ difference in outcome, and approximately $3 \%$ for on-pump. Looking at this with an eye to improving performance of OPCAB across the board, would you comment on how you might use these data going forward? What do you recommend? First, is there a volume of OPCAB that a surgeon should be doing? You gave some general ideas there. But if a surgeon is not performing more than 30 or 40 CABGs per year, should he/she do on-pump versus off-pump?

Dr Lapar. Those are both important points. I wasn't necessarily surprised to see that there was a statistically significant surgeonvolume relationship for OPCAB. That is fairly well known. One of the important points is that the difference in the adjusted probability of death that occurs from low- to high-volume surgeons falls in a continuum of anywhere from $1 \%$ to $5 \%$. The $5 \%$ value that we noted on the top end was for 1 year, and that year was back near the beginning of our analysis.

In terms of recommendations, I would be hesitant, on the basis of an observational study like this, to recommend a specific threshold for surgeons to strive for, especially in light of the fact that although this is a statistically significant relationship, the strength of associations is lower than other factors, even, for example, hypertension.

Dr Bolman. Finally, if you look at this conversely, is there a mechanism whereby surgeon or system performance can be improved even for lower-volume surgeons and programs to the level observed in the higher-volume programs, by focusing on quality, for example, the National Quality Forum standards? I raise this issue because of the earlier article by Kurlansky and colleagues, where they found no correlation between volume and outcome for $\mathrm{CABG}$ across the board and found that quality issues were more important than volume. Would you care to comment on that?

Dr Lapar. Of course, quality issues, as you mentioned, are difficult to assess in a study like this, but we would recommend centers that are proven centers of excellence in this respect, regardless of their volume.

Dr Bolman. This type of comparative effectiveness research is extremely important as we look at the adoption of new techniques.

Dr Richard Shemin (Los Angeles, Calif). Very nice study. Do you have any data to suggest that low-volume OPCAB surgeons perform operations in higher-risk patients and that the higher-volume surgeons have a better distribution of the other risk factors in their cohorts?

Dr Lapar. No, we don't have those data, and we didn't analyze the data that we do have with respect to that. That is an important observation, though. I would suspect that higher-volume surgeons have a wider distribution in the patients they see, and it may even be that low-volume surgeons, although patients may be at high or low risk, are a factor.

Dr Gregory Hirsch (Halifax, NS, Canada). Congratulations on an excellent study. From time to time, we have used administrative data in Canada for a Pan-Canadian look at various problems using Canadian Institutes of Health information data, and we have always been concerned about data quality and accuracy whenever possible, and in 1 to 3 provinces, we can invariably seek to validate the dataset we have with detailed observational data. Did you have any opportunity to do that when there is a statewide initiative, and there are several in the United States, to match up your observational data?

Dr Lapar. You point out an important limitation in secondary analyses of administrative databases. Currently we haven't had a chance to validate these results in any sort of a surgical database or a more specific quality initiative database. We do have a state quality initiative database that provides Society of Thoracic Surgeons' data within the Commonwealth of Virginia. However, our decision to use this particular administrative database is surely to obtain a reasonable sample size from which to analyze this question. The database that we have access to currently just didn't have sufficient numbers to do that. I do think this should be validated in a larger nationwide surgical database, such as the Society of Thoracic Surgeons' adult cardiac database, if possible.

Dr Valavanur Subramanian (New York, NY). Several years ago at this society's annual meeting, we presented the incremental risk of emergency OPCAB conversion on mortality and morbidity in our own large database. Is there any way to identify the conversion in this national database sample? A low-volume surgeon perhaps may have a higher emergency conversion contributing to higher mortality correlation to surgical volume. A reduction in conversion rate in $\mathrm{OPCAB}$ by routine use of intracoronary shunt and cardiac positioning device may be helpful. This is an earlier study, and most people would use a positioning device. Do you have any comment?

Dr Lapar. Within this database, it would be possible to come up with a scheme to identify within the same hospitalization whether or not a patient had 1 or both operations. As we discussed earlier in the afternoon in a similar study, there are some procedure variables within the NIS dataset that allow you to identify the day that operations are performed. But I think using those in a setting like this makes some broad assumptions that I don't know if I feel comfortable doing. I think those questions are better addressed with more specific surgical databases. 